


\title{
O espaço florestal de Alcobaça nos séculos XVIII e XIX
}
Autor(es):
Maduro, António Valério
Publicado por: Instituto de História Económica e Social, Faculdade de Letras da Universidade de Coimbra

URL persistente:

URl:http://hdl.handle.net/10316.2/9702

DOI:

DOI:http://dx.doi.org/10.14195/0870-4147_41_2

Accessed : $\quad$ 26-Apr-2023 16:06:04

A navegação consulta e descarregamento dos títulos inseridos nas Bibliotecas Digitais UC Digitalis, UC Pombalina e UC Impactum, pressupõem a aceitação plena e sem reservas dos Termos e Condições de Uso destas Bibliotecas Digitais, disponíveis em https://digitalis.uc.pt/pt-pt/termos.

Conforme exposto nos referidos Termos e Condições de Uso, o descarregamento de títulos de acesso restrito requer uma licença válida de autorização devendo o utilizador aceder ao(s) documento(s) a partir de um endereço de IP da instituição detentora da supramencionada licença.

Ao utilizador é apenas permitido o descarregamento para uso pessoal, pelo que o emprego do(s) título(s) descarregado(s) para outro fim, designadamente comercial, carece de autorização do respetivo autor ou editor da obra.

Na medida em que todas as obras da UC Digitalis se encontram protegidas pelo Código do Direito de Autor e Direitos Conexos e demais legislação aplicável, toda a cópia, parcial ou total, deste documento, nos casos em que é legalmente admitida, deverá conter ou fazer-se acompanhar por este aviso. 



\title{
O espaço florestal de Alcobaça nos séculos XVIII e XIX
}

\author{
António VALÉRIo Maduro \\ Centro de Estudos Transdisciplinares para o Desenvolvimento \\ avmaduro@gmail.com
}

\section{Resumo:}

Com a entrada do século XVIII intensifica-se a desflorestação nos coutos de Alcobaça. A mata primitiva de folhosas da Serra dos Candeeiros sofre arroteamentos para as plantações extensivas de olival. Em contrapartida, o pinhal principia a expandir-se na orla marítima fornecendo lenhas e madeiras e protegendo as campinas de milho e arroz dos ventos mareiros e avanço dunar. O liberalismo contribuiu para reduzir a área e alterar o regime de exploração das matas pondo em causa a sua sustentabilidade.

Palavras chave:

Cister; Coutos de Alcobaça; Floresta.
Abstract:

At the beginning of the 18th century the deforestation in Alcobaça manors is intensified. The primitive broadleaved forest of Serra dos Candeeiros is cleared for the extensive olive plantations. On the other hand, the pine forest starts to expand on the sea border providing wood and timber and protecting the corn and rice fields from the sea winds and dune advance. Liberalism contributed to reduce the area and change the exploitation system of the woods, thus endangering their sustainability.

Keywords:

Cister; Alcobaça manors; Forest. 
Povoamento Florestal na Comarca de Alcobaça (séc. XIX)




O sistema agrário que os monges de Alcobaça conceberam e desenvolveram no seu domínio senhorial tem de ser lido através de um eixo religioso, ideológico e moral, eixo esse que se articula intimamente com as políticas de ordenamento do território, das relações de propriedade e de produção. Esta matriz de exploração do solo, à semelhança da vida monástica, perfilha princípios de ordem, regra, ritmo e beleza numa arte matemática criada para urdir os seres e as coisas.

O controlo e a domesticação da natureza através da inseminação da terra e reprodução dos frutos revelam o pólo criativo de Cister na construção da paisagem. A Ordem Cisterciense, embora reconhecidamente de essência contemplativa, dedicou-se à gestão do território e ao trabalho manual, associando os rituais de oração à produção de frutos da terra. Nas suas Granjas praticaram a selecção de culturas arvenses e fruteiras, aprimoraram a arte da enxertia, definiram critérios de rotação, alternância cultural e compasso, apostaram em culturas estremes renunciando à promiscuidade cultural, desembaraçaram-se do pousio com novos afolhamentos, colocaram a engenharia hidráulica ao serviço das culturas e unidades industriais, cuidaram da mancha florestal, investiram nas virtudes da racionalização, inovação e experimentação agronómica.

Senhores das terras, da energia das águas, do fogo e dos ventos, dos homens e do conhecimento do mundo das plantas, assim se podiam definir os cistercienses de Alcobaça.

Os Coutos, a partir de finais do século XIV, estendiam-se por mais de 40.000 hectares, abrangendo um horizonte que da cumeeira da Serra dos Candeeiros alcança o oceano e uma orla litorânea que vai de Salir do Porto a Moel ${ }^{1}$. Compreendiam 13 vilas, das quais 3 eram portos de mar $^{2}$, onde habitava uma população atraída por políticas estratégicas de colonização e de produção de excedentes e mercancia. A coesão e organização económica e administrativa do espaço impressionou favoravelmente um erudito como Leite de Vasconcelos levando-o a considerar que “ (...) as povoações dos Coutos (...) constituíam verdadeiramente uma região - uma subdivisão geográfica da Estremadura Cistagana"”.

1 Joaquim Vieira Natividade, “As Granjas do Mosteiro de Alcobaça”, in Obras Várias II, sd, p. 59.

2 Tinham título de vila as seguintes povoações: Alfeizerão, Aljubarrota, Alvorninha, Cela, Cós, Évora de Alcobaça, Maiorga, Paredes, Pederneira, Salir de Matos, Santa Catarina, S. Martinho e Turquel. As localidades de Paredes, Pederneira e S. Martinho eram portos de mar.

3 José Leite de Vasconcelos, Etnografia Portuguesa, Vol. II, Lisboa, Imprensa Nacional-Casa da Moeda, 1980, p. 500. 
A paisagem dos coutos gozava de uma diversidade surpreendente, entre altos e baixos, corredores de colinas, cursos de água que sulcam vales e planícies, um clima amável às culturas, um solo propício à lavoura, reserva de matas de folhosas e pinhal, enseadas e baías afáveis a bons portos de pesca e comércio...

Todo o sucesso do domínio cisterciense estava articulado com uma sábia gestão e exploração das matas, área indispensável e complementar ao universo da lavoura. Na realidade, para as sociedades e economias rurais, a floresta constitui um recurso de primeira grandeza imprescindível ao bom desenvolvimento da vida material. O anel florestal é um espaço vital numa sociedade que tem na madeira a principal matéria-prima. As madeiras são indispensáveis no travejamento do edificado, na indústria naval, nas artes da tanoaria, canastraria e cestaria, na produção de instrumentos, alfaias e máquinas. Mas a floresta ecológica e ambientalmente diversa ainda fornece lenha e carvão, combustíveis utilizados no aquecimento e confecção de alimentos e no abastecimento das caldeiras industriais, matos para estrumes, camas e currais de gado e outros subprodutos utilizados nas indústrias, como a casca das folhosas (carvalho, azinho e o entrecasco dos sobreiros) aplicadas nos curtumes, a cortiça utilizada como vedante de vinhos, em aparelhos de construção com a função de isolante, na indústria de pesca e em cortiços de abelhas (cortiça virgem), frutos e fungos com que se alimentam homens e animais, medronho para a destilação de aguardentes, território de pascigo para rebanhos de ovinos e caprinos e montado de porcos, de apicultura, artes de caça e recolecção ${ }^{4}$.

A reserva florestal do Mosteiro era um espaço de uso regulado e controlado ${ }^{5}$. A política florestal monástica conseguiu, na longa duração, assegurar o equilíbrio das matas evitando os cortes abusivos de paus e pernadas reais ${ }^{6}$, a colecta de casca para curtumes, bem como fomentar o repovoamento de sobreiros e carvalhos e enxamear, a partir dos finais do século XVIII, de pinhal a orla marítima criando disponibilidades de madeira e energia e propiciando um anteparo cultural às férteis campinas da Maiorga, Cela, Valado e Alfeizerão ${ }^{7}$.

4 Maria Carlos Radich e Fernando Oliveira Baptista, "Floresta e Sociedade: Um Percurso (1875-2005)", Silva Lusitana, 13 (2005), p. 145.

5 Os forais Manuelinos autorizavam o corte de lenhas e madeiras para fins de apeiragem e lavoura, edificação de casas, o que incluía não só o espaço doméstico, como, também, as múltiplas dependências agrícolas que lhe estavam geminadas, para lareiras e fornos e mesmo para a construção de embarcações, desde que fosse previamente notificado o mateiro, Forais Manuelinos. Estremadura, (Direcção, edição, transcrição e notas por Luís Carvalho Dias), Lisboa, 1962, pp. 149-150, 316.

6 Designa os principais ramos de uma árvore.

7 Veja-se: Iria Gonçalves, O Património, cit., p. 102-104; A.N.T.T., Mosteiro de Alcobaça, Livro das Despesas Mosteiro de Alcobaça, nº 5, mç. 5, cx. 132.;. B.N.L., códice 1490, fl. 42. 
Mas esta lógica de preservação não implicou a manutenção integral das matas primitivas. Como explicita Iria Gonçalves para o período medieval a regressão dos incultos não é uma novidade, tendo-se verificado, ao longo do tempo, sucessivas arroteias que fizeram recuar o perímetro florestal, rasgando avultadas clareiras, que cindiam a floresta e até consentiam povoados no seu seio $^{8}$. As matas embora imprescindíveis não podiam travar a colonização do espaço, a necessidade de ampliação das rendas do Mosteiro e a produção de excedentes que alimentavam a mercancia.

A pressão agrícola sobre incultos e florestas começa, no entanto, a dar particulares problemas no século XVIII. Embora a supressão de matagais e a desflorestação não constituísse uma novidade, a intensidade do fenómeno tornou-se preocupante. Frei Manuel de Figueiredo, na resposta ao inquérito da Academia Real das Ciências de 1787, alerta para este risco de perca de sustentabilidade quando denuncia que: "Huma das cauzas que arruína nesta Comarca a agricultura he estar muito cultivada, de que se segue faltarem mattos para estrumes, e pastagens e os Lavradores não tirarem dos seus trabalhos as utilidades que estes podião produzir" " $\mathrm{O}$ mesmo autor, dando resposta ao item 50 do referido inquérito, em que se indaga se os lavradores "estrumão as terras, ou são tão férteis que não precisão de estrume para produzirem", declara que "como nesta Comarca há falta de matos, não pode haver abundância de estrumes" acrescentando que as terras "produzirião mais, se fossem bem estrumadas, como vemos em outras, que os lavradores adubão com bons estercos"10.

Nos coutos de Alcobaça a área de baldios e floresta sofreu uma ampla regressão comprometendo o necessário equilíbrio entre incultos e campos de cultivo ${ }^{11}$, ameaçando até a sobrevivência das actividades silvopastoris, em virtude das

8 Iria Gonçalves, O Património..., cit., pp. 163-164.

9 Biblioteca Nacional de Lisboa, códice 1490, fl. 42. O fomento da arte agrícola provocava, cada vez mais, a retracção das terras de uso comum. Esta realidade é corroborada no relatório agrícola elaborado pelo Presidente da Câmara de Alcobaça. Refere o autarca que "depois da extinção dos Frades tem melhorado a industria rural (...) tendo diminuído os mattos, baldios, e lenhas (...)". Arquivo Distrital de Leiria, Governo Civil, Actividades Económicas, Agricultura, cx. 8 (1834-1854), "Reflexões sobre a industria agricula do Concelho de Alcobaça (1839)".

${ }^{10}$ B.N.L., Perguntas de Agricultura dirigidas aos lavradores de Portugal, Academia Real de Sciencias de Lisboa, 1787; B.N.L., códice 1490, fl. 45.

${ }^{11} \mathrm{O}$ antropólogo George Estabrook, ao estabelecer uma relação biunívoca entre o sistema agrícola tradicional e as áreas baldias, sustenta que para assegurar a fertilidade de um hectare de terra cultivada é necessário dispor de mato roçado de oito hectares. George Estabrook, "Maintenance of Fertility of Shale Soils in a Tradicional Agricultural Systems in a central Interior Portugal" in Journal of Ethnobiology, 14 (1998), pp. 15-33. 
extensas plantações de olival conduzidas pelo Mosteiro nas faldas da Serra dos Candeeiros ao longo do século XVIII ${ }^{12}$.

Mas a desflorestação constitui um fenómeno nacional que não se pode circunscrever ao território alcobacense. Como explicita Nicole Devy-Vareta, quando se fala em desarborização nos séculos XVIII e XIX é necessário precisar que o discurso está sobretudo condicionado pela crescente necessidade de árvores de grande porte para o arsenal da marinha, não se colocando o problema nodal nas utilizações vulgares do parque florestal que a vida social e material das populações exige ${ }^{13}$. Mas, como vimos, nas terras de Alcobaça os usos e precisos das matas e matos para garantir a vida das populações rurais tornava-se dia a dia mais precário.

Com o desmantelamento das estruturas do Antigo Regime e a construção do edifício jurídico-político liberal assiste-se à conversão dos bens da coroa e dos organismos eclesiais em bens nacionais, revertendo para o Estado todas as terras e direitos que pertenciam aos antigos comendatários e donatários (bens esses que foram colocados em hasta pública para financiar o Estado alimentando uma complexa e profusa rede clientelar burguesa). A propriedade muda de mãos, mas esta transferência implica uma nova fundamentação social, o que na prática anuncia a vitória do utilitarismo capitalista ${ }^{14}$.

As matas reais e eclesiásticas mudam abruptamente de proprietários. O Estado apenas consegue assegurar um património florestal residual. A Administração-Geral das Matas criada por alvará de 24 de Julho de 1824, instituto dependente da Secretaria de Estado da Marinha, restringe-se, inicialmente, ao património da Coroa, mancha florestal confinada a uns escassos 14.464 hectares (dos quais o Pinhal de Leiria representava 10.000 hectares $)^{15}$. Esta superfície vai-se alargando com posteriores incorporações, graças à nacionalização dos bens das ordens

${ }^{12}$ Joaquim Vieira Natividade, A Região de Alcobaça. Algumas Notas para o Estudo da sua Agricultura, População e Vida Rural, sd, p. 89; Frei Fortunato de S. Boaventura, História Cronológica e Crítica da Real Abadia de Alcobaça, 1827, p. 31.

${ }^{13}$ Nicole Devy-Vareta, "Investigación sobre la Historia Florestal portuguesa en los siglos XIX y XX: Orientaciones y lagunas”, Historia Agraria, 18 (1999), pp. 66-67.

${ }_{14}$ Margarida Sobral Neto, "As estruturas agrárias: a força da tradição", Revista de História. Porto. Vol. X (1990), pp. 129-135.

15 Joaquim Ferreira Borges, "A Silvicultura em Portugal” in Exposição Nacional do Rio de Janeiro. Notas Sobre Portugal, Vol.I, Lisboa, Imprensa Nacional, 1908, pp. 307-308; Nicole Devy- Vareta e António Monteiro Alves, "Os avanços e os recuos da floresta em Portugal - da Idade Média ao Liberalismo" in Árvores e Florestas de Portugal. Floresta e Sociedade. Uma história em comum”, Lisboa, Público, 2007, p. 73. A área do Pinhal de Leiria continua a expandir-se alcançando na década de 8011.476 hectares. Assembleia da República, Diário da Câmara dos Senhores Deputados, 53, 18 de Março de 1880, fl. 1011. 
religiosas masculinas, nomeadamente as do Mosteiro de Alcobaça que contava nos seus coutos com 1.900 hectares de matas ${ }^{16}$. Em 1847, a Administração-Geral das Matas geria apenas 18.000 hectares, o que demonstra cabalmente que as matas dos institutos religiosos foram tomadas por particulares. Mas é com a lei de desamortização dos baldios (1869) que a floresta do Estado ganha escala $^{17}$. Estas desanexações ao logradouro comum dos povos geram resistências e traduzem-se em grandes dificuldades para a lavoura campesina que dependia do uso destes espaços para fertilizar as terras de cultivo ${ }^{18}$, conduzindo a atrasos na emancipação global do pousio e opção por novos afolhamentos, levando ainda a quebras acentuadas de produtividade do solo...

O programa político e económico regenerador ao dotar o país de redes viárias e ferroviárias, ao apostar na criação do ensino superior agrícola (1869) e no curso de Regentes Florestais (1887) favoreceu o desenvolvimento da frente florestal. A arborização das Serras, das dunas costeiras e a extensão do montado no Sul passa a ser encarado como um desígnio nacional. A floresta começa a ser considerada numa perspectiva industrial de rentabilidade segura, como fornecedora de cortiça, madeiras e resinas. A própria crise da vinha assediada pelo oídio e a filoxera, associada à imprevisibilidade produtiva do trigo, desviou a atenção do investimento privado para as florestas.

A doce relação entre o improdutivo e o produtivo deixa de ser consensual, a doutrina fisiocrata que domina o pensamento das elites intelectuais e políticas ao longo do século XIX olha para o inculto com a maior repulsa. O bravio, a natureza que não foi civilizada pelo trabalho, torna-se um empecilho ao progresso material, social e moral da nação. A regeneração da pátria pela lavoura de pão e florestação monocultural das áreas consideradas marginais ao cereal entra definitivamente na ordem do dia ${ }^{19}$.

${ }^{16}$ Nicole Devy-Vareta, “A Floresta na Memória e no Futuro do Espaço Rural” in Carlos Alberto Medeiros (dir.), Geografia de Portugal. Actividades Económicas e Espaço Geográfico, vol III, Lisboa, Círculo dos Leitores, 2005, p. 125.

${ }_{17}$ Américo Carvalho Mendes e Liliana Meneses Fernandes, "Políticas e instituições florestais em Portugal - desde o final do Antigo Regime até à actualidade" in Árvores e Florestas de Portugal. Floresta e Sociedade. Uma história em comum”. Lisboa, Público, 2007, p. 85.

${ }_{18}$ Margarida Sobral Neto, "Biens et usages communaux au Portugal (1750-1950)". In Marie-Danielle Demélas; Nadine Vivier (dir.), Les propriétés collectives face aux attaques libérales (1750-1914): Europe occidentale et Amérique latine. Rennes: Presses Universitaires de Rennes, 2003, pp. 175-194.

${ }^{19}$ Sobre este assunto vide Helder Adegar Fonseca, "A ocupação da terra”, in Pedro Lains e Álvaro Ferreira da Silva (org.), História Económica de Portugal 1700-2000, Lisboa, Imprensa de Ciências Sociais, 2005, pp. 106-108. 
Passamos, de seguida, a precisar a evolução da mancha florestal dos coutos de Alcobaça, nomeadamente das áreas de carvalhos e sobreiros, dos soutos e do pinhal.

\section{As Matas de carvalhos e sobreiros}

Ao longo dos séculos XVIII e XIX, as matas de Alcobaça sofreram uma desflorestação galopante. Às necessidades de madeira para o arsenal da marinha, construção civil, lenhas, equipamentos, utensilagens, usos de lavoura, juntava-se a voracidade dos carvoeiros que consumiam integralmente o arvoredo, mas a causa maior deste holocausto que atinge o coberto vegetal prende-se com a necessidade de obter terra produtiva, de colher mais cereais e azeite.

As matas vergam-se ao labor dos homens que, de arroteia em arroteia, as vão sangrando. Este foi o destino da mata de folhosas que ocupava a extensa planura que ladeia a Serra dos Candeeiros. Raros são hoje os trechos desta primitiva mata de carvalhos, a que se associavam outras espécies, em maior ou menor número, como o sobreiro, o zambujeiro e, em certos recantos, o loureiro, o salgueiro, o choupo, o freixo, o medronheiro, etc. O coberto antigo cede lugar à mancha de olival que numa disciplina geométrica toma conta do território. Estas fruteiras, que dão luz às casas e altares, os óleos alimentares e de unção, são as grandes responsáveis pelo extermínio das suas parentes.

Os olivais das Ataíjas (S. Vicente de Aljubarrota), de Val Ventos (Turquel) e outros de menor dimensão que, gradualmente, se vão disseminando neste plaino, confinam a nichos os carvalhos outrora dominantes. Por sua vez, o olival impulsiona o povoamento nesta área quase erma. Crescem os antigos povoados e colonizam-se novos espaços. Para abastecer as populações provocam-se novas arroteias, requisitando para a cultura agrícola a terra que dantes servia para pastoreio, aproveitamento de madeiras, lenhas, matos, montarias ao javali e ao lobo.

O maior espaço de mata, no território dos Coutos, localizava-se em torno do lugar do Gaio (Vimeiro), com uma circunferência calculada que ultrapassava a légua e meia. Estas matas estavam adstritas à Granja do Vimeiro. Como nos elucida o Corregedor de Alcobaça, no seu relatório sobre o estado e valia das matas do Mosteiro (1834), estas confinam umas com as outras, dividindo-se "naturalmente pela sua configuração em talhões". Temos então quatro matas que se abraçam. A mata do Gaio, a da Roda, a da Ribeira e a das Mestras ou Mestas. A sua área total compreende 366,71 hectares, ocupando destes a mata 
do Gaio 109,45 hectares, a da Roda 103,40, a do Canto e da Ribeira 57,49 e a das Mestras 96,3720.

Diz-nos o Corregedor que as avaliações que conseguiu fazer destas matas não primam pela exactidão e rigor "porque são feitas por carvoeiros que só entendem o valor que ellas terião se fossem para reduzir a carvão, e não sabem fazer a differença do merecimento das madeiras de prestimo" ${ }^{21}$. Considera o autor que as matas têm um valor superior àquele que é referenciado pelos carvoeiros. A mata do Gaio é avaliada em vinte e cinco contos, a da Roda em doze, a da Ribeira (que inclui uma mata de menor dimensão denominada do Canto) em dezoito e a das Mestras em dois contos e duzentos mil réis. O montante global desta avaliação cifra-se em cinquenta e sete contos e duzentos mil réis. Esta avaliação diz apenas respeito às madeiras e não ao terreno que o magistrado reputa ser de óptima qualidade, com vales abundantes de água, aprazível à cultura de cereais e vinho ${ }^{22}$.

O relatório do corregedor dá-nos preciosas indicações sobre a natureza e qualidade deste coberto florestal. Estas matas são "quasi todas de madeira de carvalho e tem muito pouco sobro". A excepção vai para a mata das Mestras (Santa Catarina), em que o carvalho português surge consociado com o sobreiro em proporção equivalente ${ }^{23}$.

${ }^{20}$ Joaquim Vieira Natividade, A Região de Alcobaça. Algumas Notas para o Estudo da sua Agricultura, População e Vida Rural, Obras Várias, Vol. I., Alcobaça, sd, p. 117.

${ }^{21}$ Arquivo Histórico do Ministério das Finanças, Mosteiro de Alcobaça, cx. 2193, "Relatório do Corregedor Interino de Alcobaça Francisco Pimentel de Mendonça sobre as matas desta circunscrição", (1 de Julho de 1834). Entende-se por "madeiras de préstimo", as madeiras fornecidas por árvores de grande porte, aplicadas, preferencialmente, na construção naval.

${ }^{22}$ A.H.M.F., Mosteiro de Alcobaça, cx. 2193, "Relatório do Corregedor..." J. Vieira Natividade, no seu estudo sobre as matas do Vimeiro, corrobora esta imagem realçando tanto a graciosidade orográfica, como a generosidade do solo para frutificar. "São como que cordilheiras de pequenos outeiros, que se cruzam em todos os sentidos, formando uma rede aparentemente inextricável. Vales largos e pouco profundos, encostas de inclinação suave, coroadas por cabeços onde o solo é menos profundo, mas apto ainda para a própria produção agrícola”. Joaquim Vieira Natividade, O Carvalho Português nas Matas do Vimeiro, Relatório do Curso de Engenheiro Silvicultor do Instituto Superior de Agronomia, (doc. polic.), 1929, p. 15.

${ }^{23}$ A.H.M.F., Mosteiro de Alcobaça, cx. 2193, "Relatório do Corregedor...". Segundo Margarida Reis, o carvalho cerquinho predomina nas matas ou trecho de matas de Alcobaça, termas da Piedade, Évora de Alcobaça, Vimeiro, Turquel e Benedita e também é frequente nas matas de Prazeres e S. Vicente. Maria Margarida Reis, O Concelho de Alcobaça. Alguns Aspectos da sua Economia Agrícola, F.L.U.C. (doc. polic.), 1961, pp. 188-189. J. Vieira Natividade menciona algumas incursões do carvalho negral nas charnecas de Turquel e Benedita, assim como de Quercus Robur nas matas do Vimeiro. Joaquim Vieira Natividade, O Carvalho..., cit., p. 17. Sobre a geografia do coberto arbóreo das matas e, em particular, da população de carvalhos veja-se: Orlando Ribeiro, Herman Lautensach, Suzanne Daveau, Geografia de Portugal - 
Interesses políticos associados a pressões por parte das oligarquias rurais e urbanas, de investidores e especuladores, naturalmente desejosos de se apoderarem dos teres e haveres das ordens religiosas suprimidas, levam a que o real valor das matas (incluindo árvores e terrenos), à semelhança de outros bens, seja manifestamente diminuído. A totalidade desta floresta é avaliada em dezoito contos, trezentos e setenta mil réis, abaixo de um terço da avaliação proposta pelo Corregedor apenas para a madeira, que o próprio já considerava fortemente subavaliado ${ }^{24}$.

Debateu-se na Câmara de Deputados a manutenção ou a alienação deste património. Venceu a tese da preservação pela consideração que este tracto de matas representava. Salienta-se a particular importância da “(...) mata de sobreiros do Vimeiro, que tanto por sua proximidade ao mar, e fácil transporte, como pela escassez que ha no reino desta madeira de construcção, deve ser de um grande recurso para a nossa marinha" 25 .

O estado das matas já era preocupante na primeira metade do século XIX. Por um lado, a falta de desvelo com que eram tratadas, acusando o coberto demasiadas mutilações. A esta história de abandono acrescente-se o grande corte de madeira para o arsenal da marinha, realizado no início do século ${ }^{26}$. Este derrote de árvores de grande porte originou, por seu turno, vastas clareiras na mata, que os povos sedentos de terra arrotearam para o cultivo de cereais, o que impedia o repovoamento natural.

Embora depauperadas por tanta flagelação, o Corregedor reconhece que estas matas ainda possuem "árvores de préstimo" capazes para empreitadas navais e para a feitura de traves e abarrotamento para a construção civil ${ }^{27}$.

Para revitalizar as matas e ajudá-las a recuperar o esplendor perdido, o Governador Civil de Leiria, em ofício enviado a 14 de Outubro de 1835 ao Ministério dos Negócios do Reino, recomenda que se proceda à abertura

II - O Ritmo Climático e a Paisagem, Lisboa, Edições Sá da Costa, pp. 548-554; Maria Carlos Radich e António Monteiro Alves, Dois Séculos de Floresta em Portugal, Lisboa, Edição Celta, 2000 , p. 50.

${ }^{24}$ A.H.M.F., Mosteiro de Alcobaça, cx. 2193, Mapa demonstrativo dos bens pertencentes ao suprimido convento de S. Bernardo de Alcobaça, seus valores e rendimentos no ano de 1834 . A mata da Roda é avaliada em 4.072.000 réis, a do Gaio em 10.000.000, a mata da Ribeira em 2.000.000 e a do Canto, com um trecho de Pinhal, em 1.650.000.

${ }^{25}$ Assembleia da República, Diário da Câmara dos Senhores Deputados, 16, 7 de Fevereiro de 1835 , fl. 239.

${ }^{26}$ Segundo o Ministro da Marinha têm-se realizado cortes sistemáticos nas matas de Alcobaça que rondam as três mil carradas. Assembleia da República, Diário da Câmara dos Dignos Pares do Reino, 16, 7 de Fevereiro de 1835, fl. 240.

${ }^{27}$ A.H.M.F., Mosteiro de Alcobaça, cx. 2193, "Relatório do Corregedor...". 
de aceiros para evitar a propagação de fogos, à administração de cuidados culturais como podas e tratamentos contra a lagarta, à realização de sementeiras e plantação de novas árvores para suprimir as clareiras e inviabilizar novas arroteias e tomadias populares, declarando que este empreendimento não custaria mais do que trezentos mil réis ao erário público ${ }^{28}$.

As necessidades económicas de curto prazo eram inconciliáveis com uma política de recuperação do património florestal. Para remir uma divida contraída a Francisco António da Fonseca, do Sanguinhal, o Estado concede-lhe as madeiras destas matas. Entre 1846 e 1855 realizam-se cortes e trabalhos de carvoaria. O usufrutuário não poupa as matas que "ficaram rasas como charnecas". O sangramento foi de tal monta que na mata do Gaio apenas ficaram de pé 366 carvalhos. A clemência para com estas árvores deveu-se exclusivamente a razões de repovoamento, atingindo este corte brutal carvalhos adultos cujo diâmetro variava entre os 9 e os 12 palmos $^{29}$. Esta supressão radical do arvoredo modificou substantivamente o regime de exploração, abandonando-se o sistema de alto fuste pelo talhadio, o que implica a adopção de ciclos de corte ou revoluções com o intervalo de vinte anos. Na prática cessa o aproveitamento das madeiras da mata para empreitadas civis e navais, orientando a exploração para a extracção de cascas ao serviço da indústria de curtumes e de madeiras para as artes da tanoaria.

Para além deste denso núcleo de matas, encontramos referência a outras de dimensão mais modesta. Na Quinta do Campo (Valado dos Frades) erguem-se duas matas, a da Almoinha, para a qual levantámos um contrato de empreitada para o fabrico de carvão ${ }^{30}$, e a mata da Enfesta ou Infesta. Esta última sofre o arroteamento e emparcelamento entre os anos de 1887-1892, assunto profusamente documentado nas escrituras notariais ${ }^{31}$.

${ }^{28}$ Arquivo Distrital de Leiria, Governo Civil, Expediente cx. 1 (1835-1857).

${ }^{29}$ Joaquim Vieira Natividade, $O$ Carvalho..., cit., p. 21; Assembleia da República, Diário da Câmara dos Senhores Deputados, 34, 14 de Fevereiro de 1852, fl. 137.

${ }^{30}$ Arquivo Distrital de Leiria, Cartório Notarial de Alcobaça, $1^{\circ}$ of., lv. 1, fls. 117-118, 20 de Fevereiro de 1862. Este contrato estabelecido entre um mercador de carvão de Lisboa e um carvoeiro empreiteiro da Junceira (Cela) é revelador da expressão industrial e comercial da carvoaria. Ao segundo é dado o fabrico por empreitada de todo o carvão que se pode produzir na Mata da Almoinha. Este contrato tem uma periodicidade de três meses (de Junho a Agosto), altura propícia à queima de lenha em fornos. Nele se estipula o pagamento de 500 réis por saca de carvão "limpo de tiços e murraças". O mercador tem o cuidado de precisar a dimensão da sacaria, que deverá ter "cinco palmos de largo e meio de alto".

${ }^{31}$ A.D.L., C.N.A., $1^{\circ}$ of., lv. 86, fls. 33-35, 20 de Dezembro de 1887; 1v. 89, fls. 96-97, 20 de Agosto de 1889; 1v. 96, fls. 58-59, 15 de Outubro de 1892; $10^{\circ}$ of., lv. 82, fls. 5-6, 28 de Setembro de 1887; 1v. 83, fls. 45-46, 20 de Fevereiro de 1888; 1v. 84, fls. 13-14, 30 de Julho de 1888... 
O povoamento de folhosas não se circunscreve a estas matas, insinuando-se, mais ou menos, generosamente, por toda a região. O cadastro do coberto florestal que realizámos das quintas do território de Alcobaça com base nas fontes notariais, ao longo do século XIX, permitiu-nos visualizar este povoamento.

No termo de Alcobaça, a Quinta do Refortuleiro possuía uma mata de carvalhos e sobreiros denominada do Cabeço. Esta consociação também estava presente na Quinta das Chuças (Maiorga) e na Quinta da Azenha (Cós). A mata de carvalhos estreme, ou com alguns indivíduos de outras espécies, imperava. São estas as referências para inúmeras quintas, como a do Mogo (S. Vicente de Aljubarrota), do Cabo ou da Preta, da Mata (Évora de Alcobaça), da Granja (Maiorga), da Granja de Valbom (Bárrio), da Maceda, da Pousada (Cela), da Granja (Turquel), etc.

As matas no Antigo Regime, como já vimos, eram abrangidas por regulamentos e convenções que estabeleciam os direitos de uso e serviço, nomeadamente a apanha de lenhas para aquecimento e confecção de alimentos, cama de gado e adubos para as terras de pão e o corte de madeiras para a edificação e reparação das casas e cómodos, alfaias agrícolas. Assim ficou definido nos Forais Manuelinos dos coutos de Alcobaça ${ }^{32}$, orientações que Frei Manuel de Figueiredo corrobora na resposta ao Inquérito da Academia Real de Ciências ${ }^{33}$.

Esta pressuposta liberalidade é limitada com a aquisição parcial deste parque florestal por particulares. A preocupação em proteger as matas da actividade predatória das populações prossegue na época liberal, nomeadamente através da criminalização da simples apanha de lenhas. É o que constatamos nas posturas do vizinho concelho de Porto de Mós, em que se penaliza esta prática com uma multa que vai de 200 a 2400 réis $^{34}$.

Por sua vez, nos arrendamentos que os senhorios fazem das suas quintas, existe o cuidado de registar que as matas existentes nestas propriedades não são alienadas, assim como os eventuais benefícios que os rendeiros poderão usufruir. Assim o lemos no arrendamento que faz João Pereira da Silva da Fonseca, da sua Quinta da Mata (antiga granja do Mosteiro de Alcobaça), em que proíbe, expressamente, o rendeiro de cortar "arvore alguma de prestimo nem de casca, a excessão porem das que lhes fazem misteres para as abeguarias,

${ }^{32}$ Iria Gonçalves, O Património..., cit., pp. 262-264; Forais Manuelinos. Estremadura. (Direcção, edição, transcrição e notas por Luís Carvalho Dias). Lisboa, 1962, pp. 149-150; 316;

${ }^{33}$ Refere o monge que "as madeiras servem se dellas sem regulamento de cortes para as Abegoarias, Curraes, cazas terreas e em miudos para empar vinhas e conservar latadas". B.N.L., códice 1490, fl. 50.

${ }^{34}$ Posturas e Regulamentos Municipaes da Câmara Municipal de Porto de Moz, 1848, Lisboa. 
e uzo da cozinha e forno da Quinta"35. O usufruto pode acarretar contrapartidas por parte do rendeiro. No contrato de arrendamento da Quinta da Maceda, ao arrendatário fica a obrigação de "vigiar matos, matas, soitos e pinhaes para não serem roubados, e que em remuneração deste trabalho de vigiar poderá gastar na sua cozinha, toda a lenha miuda que precisar mesmo no forno (...)"36.

No termo de vida do século XIX, as matas do Vimeiro são a pálida imagem de uma anterior grandeza. Num solo de excelência, as árvores definham e as clareiras desenham as feridas na mata. Vários factores contribuem para este estado de desolação e decrepitude. A persistência secular da cultura de uma essência em regime de exclusividade deixa de ser sustentável com o abandono do alto fuste pelo talhadio. De facto, a esgotante exploração de talhadio, com os seus ciclos de corte demasiado intensos (cerca de 20 anos), privava o solo dos nutrientes necessários ao sucesso vegetativo. Por outro lado, a esmoita regular da mata, dada com um intervalo de três a quatro anos, a que acrescia a raspa do terriço (manta morta), penalizava severamente a sua capacidade de regeneração. Esta actividade desregrada ceifava as pequenas árvores que provinham da sementeira natural, impedindo o repovoamento.

O talhadio dependia da rebentação das toiças das antigas árvores e com a morte destas rasgavam-se vazios que a floresta por si não podia preencher. A agravar este quadro negro, o carvalhal sofreu com as incursões do oídio (a acção destrutiva deste fungo torna-se mais evidente na altura da rebentação das plantas incidindo, com especial acuidade, nos regimes de exploração de talhadio) e com a depreciação económica da casca, subproduto utilizado na

${ }^{35}$ A.D.L., C.N.A., $10^{\circ}$ of., lv. 16, fls. 71-73, 11 de Outubro de 1850 . Este contrato elucida-nos também sobre a obrigação do rendeiro pagar ao senhorio 500 telhas por ano, desde que os fornos cozam e se arranque barro das barreiras da Quinta. Num contrato sequente, o senhorio altera as disposições quanto ao benefício partilhado do produto dos fornos. Incumbe-se agora ao rendeiro a obrigação de fazer transportar para Alcobaça, a expensas próprias, toda a telha proveniente da pensão imposta aos forneiros de extraírem o barro e o cozerem nesta propriedade. Em contrapartida, o rendeiro goza do privilégio de vender o mato necessário para a cozedura do barro, ressalvando-se, contudo, que o mato será vendido pelo preço justo (evitando-se assim especulações por parte do rendeiro que pudessem comprometer o funcionamento dos fornos). A.D.L., C.N.A., $10^{\circ}$ of., lv. 32, fls. 37-38, 20 de Abril de 1857.

${ }^{36}$ A.D.L., C.N.A., $10^{\circ}$ of., lv. 17, fls. 71-73, 8 de Fevereiro de 1851. Para que não subsista qualquer margem de dúvida quanto ao exercício das suas prerrogativas, alguns contratos reservam a obra que o senhorio se permite praticar no tracto de mata. Numa escritura de reconhecimento de foro que faz Luís Agostinho ao proprietário da Quinta da Pousada, Narciso Alves Monteiro, o senhorio faz saber que "reserva para si o direito de mandar cortar os carvalhos, mato, cepa, pinheiros na mata que fica ao Norte pelo espaço de quatro annos; e dentro e pelo tempo de três annos tirarem nas outras matas seis carvalhos que deem vigas, dois pinheiros e dois choupos na varzea da Horta (...)” A.D.L., C.N.A., 12ºf of, lv. 11, fls. 50-51, 24 de Outubro de 1856. 
curtimenta das peles. A perca gradual de interesse neste produto leva a que os colheteiros passassem apenas a aproveitar a capa ou capeira do pé, em que a casca é mais grossa e portanto de maior valor comercial ${ }^{37}$.

Na mata do Gaio, o povoamento de carvalho português cessa a partir de 1916. Para o substituir introduzem-se novas essências, nomeadamente o pinheiro-bravo, o eucalipto e o castanheiro. Nas matas da Roda, do Canto e da Ribeira, o carvalho conhece a concorrência do pinheiro bravo, do pinheiro manso, a que se vem juntar posteriormente o eucalipto ${ }^{38}$. Apenas na mata da Roda subsistem trechos de carvalhos de alto fuste, como ainda podemos presenciar nas imediações do manancial da Pena da Gouvinha ${ }^{39}$.

O século XX contribuiu decisivamente para a contracção das grandes matas do Vimeiro que, ao longo do século XIX, já tinham sido tão diminuídas no seu esplendor. À sobre exploração a que são sujeitas com a crise de matérias-primas combustíveis originada pela Grande Guerra e com o frenético regime de talhadio, segue-se, por meados do século, o tenaz abate e arroteamento para a instalação de pomares de fruteiras que vão ocupar os solos de primeira qualidade e relegar este coberto para as zonas mais acidentadas.

\section{Os Soutos}

Os principais soutos, no território coutado de Alcobaça, encontravam-se na Quinta do Cidral (Vestiaria), no Azevinhal, que é contíguo a esta quinta e no Vale das Maias (Casal Pereiro, Évora de Alcobaça). A exploração destes talhadios de souto bravo estava sob a administração directa da Confraria do Santíssimo Sacramento.

A cartografia dos soutos tem maior expressão nas cercanias de Alcobaça, nas terras da Maiorga, Aljubarrota e Évora de Alcobaça. O que não invalida a existência de soutos noutras vilas dos Coutos. Aliás, Frei Manuel dos Santos, na sua obra "Alcobaça Ilustrada" menciona o souto de Vale Ventos (Turquel) ${ }^{40}$. Deste souto não temos porém outras referências, pois este povoamento terá dado lugar ao fértil olival que, ao longo do século XVIII, substitui o coberto florestal autóctone da subserra dos Candeeiros.

37 Joaquim Vieira Natividade, O Carvalho..., cit., pp. 120-124, 137, 142-143, 148.

${ }^{38}$ Sobre a destruição das matas de folhosas pelo pinhal, veja-se: DEVY-Vareta, Nicole. (1999). "Investigación sobre la Historia Florestal...," cit., pp. 73-76.

${ }^{39}$ Joaquim Vieira Natividade, $O$ Carvalho..., cit., pp. 20, 22.

${ }^{40}$ Frei Manuel dos Santos, Alcobaça Ilustrada. Primeira Parte, Coimbra, 1710, p. 497. 
No início do século XX, ainda subsistiam alguns trechos de castanheiros consociados com loureiros a poente da vila de Turquel ${ }^{41}$. Também na localidade da Castanheira (Cós), a fazer jus ao topónimo, descobrem-se manchas de castanheiros ostentando árvores de porte nobre. Frei Manuel de Figueiredo, impressionado com a sua dimensão, compara-as com as suas congéneres da Beira ${ }^{42}$.

Poucas são as quintas que possuem soutos no século XIX. Para além do Cidral só encontramos notícias deste povoamento nas Quintas da Granja, Cidreiras e Chuças (Maiorga), na Quinta da Maceda (Cela), do Refortuleiro e do Botado (Alcobaça). Merece particular atenção um contrato de venda da madeira dos soutos da Quinta da Granja, efectuado pelo Barão da Costa Veiga, na qualidade de detentor do domínio útil desta propriedade, a José Rodrigues Coelho, dos Casais Caniços (Vestiaria). O clausulado da escritura é rico em informações. Ficamos a saber: “ $1{ }^{\circ}$ Que os soutos serão cortados de uma só vez (...) imperterivelmente dentro de quatro annos, contados do último corte (...) $3^{\circ}$ Que o comprador não cortará senão soutos de castanho, avelleiras, e giestas e não arrancará cepas algumas, nem cortará carvalhos, medronheiro ou outra qualquer árvore grande de castanho dos que foram marcados no último corte. $4^{\circ}$ Que o comprador fica obrigado a dar dos ditos soutos as varas precisas aos lavradores da quinta para picarem os bois, bem como as varas grandes para varejar a azeitona da mesma Quinta, e dos olivaes da serra, pertencentes a elle primeiro outorgante..."43.

Graças aos soutos de talhadio abundava a vararia que servia de matéria-prima ao ofício de canastreiro. Com a madeira rachada de castanho, produziam-se arcos para reforçar tonéis (nomeadamente, os tonéis do vinho do Porto), aduelas e vasilhas vinárias, canastras, cabaços, cabazes e cestas de correia, gigas.

Os contratos de aquisição da vararia levantados ao longo do século XIX determinam o período de execução do corte das varas, de ajuntar e tirar a madeira do souto, proíbem aos homens que andam no souto o arranque de cepas, medronheiros, ou o corte de qualquer outra árvore, incluindo "pau de souto velho", e mandam salvar os rebentões das toiças...

${ }^{41}$ José Diogo Ribeiro, Memórias de Turquel, Porto, Livraria Figueirinhas, 1908, p. 161.

${ }^{42}$ B.N.L., cód. 1490, fl. 57. Na região o termo castanheira significa um castanheiro manso ou enxertado, destinado à produção de frutos.

${ }^{43}$ A.D.L., C.N.A., $10^{\circ}$ of., lv. 54, fls. 30-31, 5 de Junho de 1870. 
Para além da aquisição da vararia em período de corte, os canastreiros ou negociantes de varas costumavam, igualmente, arrendar terras de soutos. É o caso de uma escritura de arrendamento, por tempo de dez anos (o que equivale a dois cortes), que dá Francisco Pereira da Trindade ao negociante e canastreiro Francisco Rodrigues, da Maiorga. O contrato compreende dois soutos, um no sítio do Sampaio e o outro no da Caldeira (Maiorga), com a pensão anual de 12.000 réis. Nesta escritura, o proprietário tem o cuidado de frisar “ (...) que o rendeiro fará sempre os cortes nas epochas proprias, e segundo o costume local, e nunca de modo que possa destruir as raízes a ponto de depreciação do valor que actualmente tem" ${ }^{44}$.

O valor do souto é sempre acautelado quando se arrendam propriedades em que esta madeira existe. Em algumas escrituras, o foro inclui a entrega de vararia. É o que se verifica num contrato de reconhecimento de foro da Quinta da Boavista, em que a pensão contempla, "setenta alqueires de trigo, milheiro e meio de fruta de carosso, huma carrada de madeira, e trinta e seis varas de castanho (...)"45.

Noutros contratos, o senhorio restringe ou mesmo interdita qualquer direito de usufruto da mata de castanheiros pertencente ao prédio arrendado. A regra dita que os tractos de souto existentes nas propriedades arrendadas ficavam excluídos dos contratos. Esta asserção é justificada por vários registos de escrituras que coligimos. Num contrato de arrendamento de um casal na Maiorga, denominado o Bajouco, o senhorio determina: "Que ficam excluídos desse arrendamento as souteiras que existem na propriedade arrendada, pertencendo somente aos rendeiros os fructos dellas enquanto o senhorio as não cortar para si ou para vender" 46 .

\section{Os Pinhais}

O pinheiro-bravo, com maior ou menor representação, disseminou-se por toda a região de Alcobaça. A sua plantação tem foros de modernidade. Frei Manuel de Figueiredo, na resposta ao Inquérito da Academia Real de Ciências de 1787 refere que os moradores tinham principiado a semear pinhais ${ }^{47}$.

Para semear pinhal utilizava-se, normalmente, o penisco. A sementeira de penisco, feita a lanço (alqueire e meio por jeira), era traçada com sementes de

\footnotetext{
${ }^{44}$ A.D.L., C.N.A., $1^{\circ}$ of., lv. 9 ou 68, fl. 19, 30 de Junho de 1862.

45 A.D.L., C.N.A., $9^{\circ}$ of., lv. 9, fls. 7-9, 5 de Setembro de 1847.

${ }^{46}$ A.D.L., C.N.A., $1^{\text {o }}$ of., lv. 96, fls. 94-95, 3 de Novembro de 1892.

${ }^{47}$ B.N.L., códice 1490, fl. 42.
} 
plantas arenosas (na proporção aproximada de um terço) quando se situava nos arrabaldes da linha de costa. Estas plantas ajudavam a consolidar o terreno e a proteger os pinheiros recém-nascidos dos agrestes ventos marítimos. À medida que a cultura se ia distanciando da franja costeira, trocavam-se estas sementes por aveia ou centeio, de forma a abrigar os pinheiros da canícula ${ }^{48}$.

A floresta monocultural de pinho tem sobretudo expressão económica no corredor litoral do território coutado. A maior mancha de pinhal está adstrita à Quinta do Campo ${ }^{49}$, abarcando uma superfície que, caso o contorno fosse regular, excederia uma légua quadrada ${ }^{50}$. Esta floresta tem na povoação do Valado o seu coração, abrangendo o seu corpo uma área que da Piedade alcança Fanhais e Moita para culminar à beira-mar nas pontes da Barquinha, a escassas duas léguas de S. Martinho.

O pinhal é uma guarda avançada que protege os terrenos de cultura dos agrestes ventos marítimos e da progressão dunar. O sucesso da agricultura regada nas terras de campo depende deste coberto florestal de resguardo, a par de um sistema eficaz de escoamento e distribuição das águas ${ }^{51}$.

Segundo opinião do Corregedor F. Pimentel de Mendonça, o abate desta floresta comprometia irremediavelmente "os férteis campos da quinta do Vallado, Barquinha, e todo o vale que dali se estende até Alfasirão e San Martinho”.

${ }^{48}$ Sobre o processo da sementeira do pinheiro-bravo, veja-se: José Maria Grande, Guia e Manual do Cultivador ou Elementos de Agricultura, Tomo I, Lisboa, Typographia do Panorama,1849, p. 317; António Arala Pinto, O Pinhal do Rei. Subsídios, Composição e Impressão da Oficina de José Oliveira Junior, Vol. I, 1939, pp. 397-414; Maria Carlos Baptista, A Agronomia Portuguesa no Século XIX, cit., pp. 372-376. A população de Pataias dedicava-se à apanha de pinhas que não só serviam para gastos de lareiras e fornos, como eram vendidas aos próprios serviços florestais para actividades de povoamento.

${ }^{49}$ A Quinta do Campo era uma das maiores granjas monásticas dos coutos com uma área de 551 hectares. Para além das terras de pão, nomeadamente de milho, albergava uma extensa mancha de pinhal, trechos de carvalhos, amieiros, choupos e salgueiros. S/A, Alcobaça. Melhoramentos Industriais, Lisboa, Typographia da Sociedade Typographica Franco-Portugueza, 1861 p. 20.

${ }^{50}$ Segundo Joaquim V. Natividade este pinhal ocupava uma extensão de 1.475,35 hectares. Joaquim Vieira Natividade, A Região de Alcobaça, cit., p. 117.

${ }^{51}$ O Ministro da Marinha que tutelava a Administração-Geral das Matas, compreende a importância da floresta na preservação do território, na criação de riqueza e na beneficiação da agricultura. Declara o titular que "a conservação das matas, e não só, é muito instructiva, e judiciosa; mas d'interesse publico, muita cousa se podia dizer sobre este objecto, em favor das matas, vantagem de mudar a constituição fisica, attraindo os chuveiros, embaraçando as correntes impetuosas dos ventos, retardando o movimento dos areaes, nas costas do mar, abrigando os portos, provendo a construcção de navios e barcos, ministrando combustivel, de que tanto carecemos, fornecendo os materiaes ás construcções novas; e apesar disso é preciso confessar; que estão arruinados, pelo desleixo das administrações passadas". Assembleia da República, Diário da Câmara dos Senhores Deputados, 16, 7 de Fevereiro de 1835, fl. 240. 
Culpava este magistrado os povos pela desvalorização deste prédio, pois pelo "ódio que tinhão aos seus Monges deitarão abaixo muitas madeiras e largarão-lhe fogo" 52 . Que o clima entre a população e as autoridades estava ao rubro depreende-se facilmente do ofício emanado pelo administrador do concelho, a 5 de Dezembro de 1835, ao Governo Civil, em que se participa a recusa do povo do Valado em assinar um documento que regulamentava "os usos domesticos (dos) matos, madeiras e lenhas dos Pinhais visinhos" ${ }^{53}$.

Mesmo depreciado por abates clandestinos e por incêndios, era ao tempo atribuído ao Pinhal do Valado um valor de doze contos. As suas árvores tinham préstimo para tabuados e madeiramentos para construção, sendo afiançado por peritos um rendimento anual de 400.000 réis, sem que estes cortes violem a integridade da floresta ${ }^{54}$.

Numa escala bem mais modesta que a do Pinhal do Valado ou da Pederneira, mas beneficiando da proximidade da baía de S. Martinho (aproximadamente um quarto de légua), na altura a principal barra comercial, ergue-se o Pinhal do Santíssimo. Este pinhal, avaliado em um conto de réis, possui madeiras de qualidade equivalente às do Pinhal do Valado ${ }^{55}$.

Para agilizar a expedição das madeiras do pinhal decidiu-se, no ano 1856, proceder a estudos para a abertura de uma via rolante desde o Pinhal de Leiria até S. Martinho do Porto. Em 1857, o Administrador Geral das Matas regozijava-se pela aceitação, por parte da tutela, do caminho de madeira por ele idealizado, assim como da ordem de construção de dois iates (baptizados de Marinha Grande e Valado).

As madeiras carreadas pelo comboio americano dependiam das condições do Porto de S. Martinho. A Câmara de Alcobaça, corria o ano de 1859, apresenta uma diligência junto da Câmara de Deputados para que se proceda a melhoramentos portuários urgentes. Na defesa do projecto argumenta-se que as obras

${ }^{52}$ A.H.M.F., Mosteiro de Alcobaça, cx. 2193, "Relatório do Corregedor...". Os fogos postos para aquisição posterior de madeira barata foram, provavelmente, correntes no período conturbado que sucedeu ao afastamento da Ordem Cisterciense das terras de Alcobaça. Apenas no mês de Maio de 1837 registam-se "duas arrematações de pinheiros afogueados por incendio no Vallado, uma a 41 réis cada um, e a outra a 55 réis, com a obrigação de pagarem os arrematantes cada 100 páus cortados". A.D. L., Mosteiro de Alcobaça, Sequestros., Vendas e Arrematações., cx. 8 , doc. 1 .

53 A.D.L., Governo Civil, Expediente, $1^{\text {a }}$ Repartição Administrativa, no 207, fl. 40 (1835$-1844)$, cx. 1.

${ }^{54}$ A descrição do Corregedor permite avaliar o estado de desenvolvimento do pinhal que, pelo menos, em alguns trechos devia possuir árvores entre os quarenta e os oitenta anos de idade, período de vida em que as madeiras se aprestam para estes fins.

55 A.H.M.F., Mosteiro de Alcobaça, cx. 2193, "Relatório do Corregedor...". 
são imperiosas, caso contrário, dentro de dez anos as areias inutilizam a barra "e parecerá grande disparate se ter feito um caminho de ferro, em que se gastaram 120.000 .000 , para um porto onde não ha meio de embarcar a madeira do pinhal de Leiria"56.

A linha do pinhal com 36 km de extensão partia de Pedreanes (depósito de madeiras serradas) e tinha estações de muda na Martingança, Valado dos Frades, Mouchinha e S. Martinho, onde o gado repousava. No trajecto de retorno, os vagões eram atestados de areia e pedra na Martingança para abastecer a Fábrica Nacional de Vidros.

O comboio americano era constituído por nove vagões de carga e um de passageiros e a sua tracção dependia de parelhas de gado bovino. $\mathrm{O}$ percurso tinha a duração prevista de oito horas ${ }^{57}$. O trânsito dos vagões decorria entre a segunda-feira e o sábado, disponibilizando-se uma junta por cada vagão. As fontes notariais referentes ao século XIX elucidam-nos sobre a natureza das condições contratuais estabelecidas entre os concessionários da linha e os boieiros que, com o seu gado, se vão encarregar da deslocação dos vagões entre a estação do Valado, o Pinhal do Santíssimo e o Casal do Bispo.

Num contrato estabelecido no ano de 1862 acorda-se o serviço de cinco boieiros (provenientes das localidades de Valado e Cela Velha). Apenas um deles ocupava os seus animais em permanência, alternando os restantes carreiros o gado no serviço. A remuneração da junta de gado por vagão é fixada em 390 réis $^{58}$. Já num contrato firmado no ano sequente, ficamos a saber que Maria Carvalha, boieira de profissão, tinha de apresentar na estação do Valado seis bois todas as segundas, quartas e sextas-feiras, sendo o frete anual das madeiras entregue a quatro boieiros. Esta escritura mais pormenorizada estipula "que cada junta sera obrigada a puchar somente um vagão ganhando em cada dia tresentos e sincoenta reis". Cada falta ao serviço tinha como contrapartida a indemnização de 5.000 réis. Idêntica quantia se comprometia a pagar o concessionário da linha, caso os vagões, por algum imprevisto, não comparecessem na estação. Por motivo de doença, o boieiro podia recorrer aos companheiros que nesse dia não tivessem serviço ${ }^{59}$. fl. 94.

${ }^{56}$ Assembleia da República, Diário da Câmara dos Deputados, 11, 14 de Fevereiro de 1859,

${ }^{57}$ Veja-se: António Arala Pinto, O Pinhal do Rei. Subsídios, Vol.I, 1939, pp. 378-383; João Azambuja, Cidade da Marinha Grande. Subsídios para a sua História, Marinha Grande, C. M. da Marinha Grande, 1998, pp. 118-120.

${ }^{58}$ A.D.L., C.N.A., $9^{\circ}$ of., 1v. 23, fl. 16, 26 de Janeiro $1862 \ldots$

${ }^{59}$ A.D.L., C.N.A., $9^{\circ}$ of., lv. 24, fl. 30, 20 de Dezembro de 1863. 
As madeiras provenientes das matas de Alcobaça eram exportadas em toros por falta de engenhos hidráulicos aplicados na serração. Num estudo sobre a economia do concelho e suas potencialidades de desenvolvimento elaborado em 1861 refere-se que" (...) a maior parte das madeiras até agora vão por serrar. A pouca que submetem a esta operação é serrada a braços por homens que ganham 400 réis diários". Nesta obra, lastima-se a falta de iniciativa no aproveitamento do motor hidráulico na serração de madeiras. Propunha-se a instalação de um engenho de serrar nas quedas de água da Fervença. Segundo os autores do estudo, esta queda oferecia uma potência de 50 cavalos, o que correspondia aos gastos de 616 toneladas de carvão anuais para accionar uma máquina de serrar a vapor com capacidade equivalente ${ }^{60}$.

O único engenho hidráulico de que temos conhecimento na área geográfica dos Coutos estava localizado na Cerca de Dentro do Mosteiro. Na escritura de arrendamento do moinho da Praça, celebrada a 16 de Junho de 1828, previa-se a redução da renda caso o desvio parcial do caudal da levada para accionar o "engenho da madeira" inutilizasse alguma mó do moinho. Mas este engenho de serrar já estava inactivo em 1838. No aforamento que o notável Francisco Pereira da Trindade faz à Câmara Municipal do moinho da Praça, sublinha que o contrato só será exequível desde que a Câmara lhe garanta a posse e a servidão das águas e que no local em que trabalhava o engenho não se venha a instalar outro ofício similar. O actual foreiro relembra que a laboração do engenho prejudicou, em grande medida, os anteriores rendeiros e que, por esse motivo, as pensões chegaram a ser reduzidas para um terço do valor estabelecido ${ }^{61}$.

As lenhas destas matas alimentavam um conjunto de indústrias. Levantámos para o ano de 1915 um contrato de fornecimento de lenha à Companhia de Fiação e Tecidos de Alcobaça. Nesta escritura, celebrada entre o director da empresa, Fernando Alípio Carneiro e Sá e o madeireiro Joaquim Modesto, o segundo outorgante compromete-se a fornecer à Companhia, desde 1 de Maio até 30 de Setembro, nos dias úteis de laboração, "doze a quinze toneladas de lenha de pinho, bem seca, rachada, e toros correspondentes do comprimento de um metro aproximadamente, sem ser rachados (...) em boas condições para poder entrar imediatamente nas caldeiras pelo preço de quatro escudos e cincoenta centavos cada tonelada". Obriga-se ainda o fornecedor a ter nos depósitos da empresa 60 toneladas de lenha, excluindo a de consumo diário. Caso a laboração

${ }^{60}$ S/A Alcobaça. Melhoramentos Industriais, 1861, pp. 12-13.

${ }^{61}$ A.D.L., C.N.A., $1^{\circ}$ of., lv. 3, fls. 9-11, 16 de Junho de 1828; A.D.L., C.N.A., $9^{\circ}$ of., 1v. 2 , fls. 18-22, 18 de Maio de 1838. 
seja interrompida por falta de combustível, prevê-se a indemnização de $30 \$ 00$ por cada dia de paralisação ${ }^{62}$.

Segundo Vieira Natividade, só no ano de 1921, a dita Companhia consumiu 4.814.190 quilos de lenha de pinho, realçando, este autor, que as necessidades podiam ascender aos 9.000.000 de quilos, caso esta empresa prescindisse do uso do carvão. Para satisfazer os fornos das fábricas da Empresa Cerâmica de Alcobaça ${ }^{63}$ estimavam-se consumos da ordem dos 2.000.000 quilos anuais. Estas lenhas serviam também de combustível para as indústrias vidreiras de Pataias e da Marinha Grande, para os fornos de carvão, de cal, de telha e tijolo, para os alambiques de destilação de vinhos, bagaços e frutos (figo, medronho, ameixa) ${ }^{64}$.

A rentabilidade do pinhal leva à constituição de empresas apostadas na sua exploração. A partir do ano de 1920, as escrituras notariais testemunham a actividade fabril da "Empresa Pinhais do Camarção Lda.", com sede em S.Pedro de Moel, na aquisição de terras de pinhal, pousios e bastios na freguesia de Pataias (Alcobaça) ${ }^{65}$.

No espaço serrano, o pinheiro é uma novidade e escassas são as quintas que dedicam uma parcela de terreno a esta cultura florestal. Ainda assim, surgem referenciados trechos de pinhal nas Quintas da Barrada, Castanheiro ${ }^{66}$, da Mata (Évora de Alcobaça) e Quinta de Joaquim Pereira (Prazeres de Aljubarrota). Segundo testemunho de Diogo Ribeiro, na zona ocidental da freguesia de

${ }^{62}$ A.D.L., C.N.A., $13^{\circ}$ of., lv. 32, fls. 35-37, 26 de Abril de 1915. Nos contratos sequentes obriga-se o fornecedor a manter no depósito da empresa 250 toneladas de pinho, sem contar com a lenha de consumo diário. Mais se estipula que a lenha deve ser pesada na altura da entrega e empilhada à custa do segundo outorgante. Em contrapartida, a Companhia compromete-se a não comprar lenha a qualquer outro fornecedor durante o prazo de validade dos respectivos contratos. Veja-se: A.D.L., C.N.A., $13^{\circ}$ of., lv. 34, fls. 43-45, 12 de Agosto de 1915; $13^{\circ}$ of., lv. 40, fls. 16-17, de 10 de Março de 1916; $13^{\circ}$ of., lv. 48, fls. 44-46, de 4 de Janeiro de 1917; $13^{\circ}$ of., lv. 57, fls. 48-50, de 30 de Julho de 1917; $13^{\circ}$ of., lv. 66, fls. 20-23, 30 de Janeiro de 1918; $13^{\circ}$ of., lv. 68, fls. 8-11, 24 de Março de 1918.

${ }^{63}$ Esta indústria, sedeada no Vale Amieiro (Cós), foi constituída por escritura de 23 de Fevereiro de 1920. O primeiro signatário era Fernando Alípio Carneiro e Sá que, na altura, era o director da Companhia de Fiação e Tecidos de Alcobaça. A.D.L., C.N.A., 13º of., lv. 86, fls. 44-48, 23 de Fevereiro de 1920.

${ }^{64}$ Joaquim Vieira Natividade, A Região de Alcobaça..., cit., pp. 118-119.

${ }^{65}$ Veja-se: A.D.L., C.N.A., $13^{\circ}$ of., lv. 91, fls. 25-27, 31 de Março de 1920; $13^{\circ}$ of., lv. 99 , fls. 31-34, 21 de Outubro de 1920; $13^{\circ}$ of., lv. 127, fls. 34-35, 27 de Junho de 1924; $13^{\circ}$ of., lv. 181, fls. 30-31, 1 de Agosto de 1931; $13^{\circ}$ of., lv. 287, fls. 23-24, 17 de Outubro de $1936 ; 13^{\circ}$ of., lv. 309, fls. 17-18, 15 de Janeiro de 1938; 13o of., lv. 313, fls. 10-12, 12 de Abril de 1938.

${ }^{66}$ Nas despesas correntes do mês de Setembro de 1748, levantámos a compra, por 1150 réis, de 2 alqueires de pinhões-bravos para semear na Quinta do Castanheiro. A.N.T.T., Mosteiro de Alcobaça, Livro das Despesas Mosteiro de Alcobaça, $\mathrm{n}^{\circ}$ 5, mç. 5, cx. 132. 
Turquel, o pinheiro tornou-se uma cultura comum a partir do $3^{\circ}$ quartel do século XIX ${ }^{67}$. Entre as grandes matas de carvalhos do Vimeiro, o pinhal surge nas Quintas da Mata e da Ruiva.

O cuidado com os pinhais recrudesce ao longo da segunda metade do século XIX. São elucidativas as precauções tomadas pelo proprietário da Quinta da Conceição, João Pereira da Silva da Fonseca, no arrendamento que faz desta propriedade por oito moios anuais de pão meado. Neste contrato explicita-se que ao rendeiro assiste o direito de cortar o mato, "mas de forma que o Pinhal não sofra prejuízo, porque em tal caso a renda pagará em dobro"68. Já num contrato de arrendamento de dois moinhos, na Ribeira de Fanhais (área de pinhal), o proprietário concede ao rendeiro o benefício das lenhas provenientes das braças dos pinheiros, com a contrapartida deste vigiar os pinhais e impedir o saque praticado pelo povo. O senhorio autoriza ainda o corte de algum pinheiro necessário para reparações no engenho, substituição de um cubo de tronco apodrecido ${ }^{69}$, etc.

Pelo seu crescimento rápido, quando comparado com o desenvolvimento das matas de carvalhos e sobreiros, o pinhal constitui uma fonte de rendimento apetecível, pelo que é compreensível que a sua plantação tenha disparado e que muitos estejam interessados na sua exploração. Possuir algumas bicas de pinheiro passa a ser entendido, pelas classes populares, como um sinal de desafogo económico.

A exploração dos pinhais de propriedade privada realiza-se quer pelo método da jardinagem, derrotando regularmente alguns pinheiros adultos, quer pelo sistema dos cortes rasos, abatendo integralmente a floresta ${ }^{70}$. A idade do derrote dependia das pretensões do proprietário. Para a obtenção de lenhas,

${ }^{67}$ José Diogo Ribeiro, Memórias de Turquel..., cit., 1908, p. 161. A difusão do pinhal na área serrana manteve-se ao longo das primeiras décadas do século XX. Sabemos da existência de pinhal novo na Quinta da Serra, dado que no contrato de arrendamento de uma fracção desta propriedade, celebrado no ano de 1921, se declara a exclusão do pinhal, garantindo apenas ao rendeiro algumas lenhas da limpeza para gastos de casa, assim como o direito de vender carumas e pinhas. A.D.L., C.N.A., 13º of., 1v. 110, fls. 8-12, 26 de Julho de 1921.

${ }^{68}$ A.D.L., C.N.A., $9^{\circ}$ of., lv. 22, fls. 32-33, 6 de Dezembro de 1860.

${ }^{69}$ A.D.L., C.N.A., $1^{\circ}$ of., 1v.55, fls. 66-69, 8 de Junho de 1800 . O furto de lenhas e árvores era uma actividade a que os povos recorriam para suprir as suas necessidades. Nuno Monteiro entre os anos de 1823 e 1824 analisou para cima de 8 processos que tinham como móbil o roubo de pinheiros no pinhal do Valado. Esta atitude ousada e recorrente por parte dos populares deve, sem dúvida, explicar-se à luz da perturbação social que varria as terras dos coutos. Nuno Monteiro, "Lavradores, Frades e Forais. Revolução Liberal e Regime Senhorial na Comarca de Alcobaça (1820-1824)" in Ler História, 4 (1985), p. 59.

${ }^{70}$ Joaquim Vieira Natividade,. A Região de Alcobaça..., cit., p. 118. 
o corte era executado entre os 35 e os 40 anos. Quando o objectivo consistia na produção de tabuado, a esperança de vida do pinhal podia alcançar os 60 anos. Para barrotado e vigamentos as madeiras só estavam aptas dos 60 aos $80 \operatorname{anos}^{71}$. Era usual deixar alguns pinheiros sementões, para repovoamento, cuja idade podia exceder um século.

$\mathrm{O}$ interesse acrescido nesta cultura, aliado à valorização destas terras, leva a Câmara Municipal, em 1885, a alienar património florestal no Casal da Areia (Cós) e em Alfeizerão ${ }^{72}$. A venda dos pinhais municipais representou, de facto, uma fonte de financiamento de que a edilidade se socorreu para pôr em marcha obras de interesse público, com particular realce para os trabalhos de captação e adução das águas de Chiqueda para a sede do município ${ }^{73}$.

$\mathrm{O}$ desenvolvimento da indústria de resinagem, no ocaso do século XIX, constituiu outra fonte de rentabilidade que o pinheiro-bravo propiciava ${ }^{74}$. A resinagem do pinheiro-bravo faz-se à morte, dando-lhe os cortes para a extracção da resina apenas alguns anos antes do abate. No ano de 1894 sangraram-se cerca de 400.000 árvores no conjunto dos concelhos de Leiria e Alcobaça, estendendo-se, paulatinamente, esta nova indústria a outros territórios do país em que o pinheiro ganhava soberania ${ }^{75}$. Num "contrato de exploração ou extracção de resina" dos pinhais da Real Casa de N. Sr. da Nazaré estabelecido em 1901 entre a Administração desta instituição e Joaquim Modesto (resineiro e madeireiro que fornecia a lenha para as caldeiras da Fiação e Tecidos de Alcobaça) levanta-se um conjunto de condições e regulamentações da actividade. Fica-se a saber que os trabalhos "não podem principiar antes do dia 1 de Março nem terminar depois de 30 de Novembro; que o arrematante só poderá meter uma ferida em cada pinheiro, que estiver nas condições de ser

${ }^{71}$ Sobre a correspondência entre a idade e o aproveitamento económico do pinhal, veja-se: PIMENTEL, C. A. de Sousa, "Os Pinhais" in Jornal Oficial de Agricultura, Artes e Ciências Correlativas, Vol. III, Lisboa, Imprensa Nacional, 1880, p. 135.

${ }^{72}$ B.M.A., lv. 19 dos Acórdãos das Sessões da C.M.A., fl. 125, 30 de Junho de 1885.

${ }^{73}$ B.M.A., lv. 20 dos Acórdãos das Sessões da C.M.A., fl. 29, 19 de Junho de 1886.

${ }^{74}$ No concelho de Alcobaça constitui-se, no ano de 1934, a "Sociedade Resineira Portuguesa, Lda.”, firma comercial com sede em Valado dos Frades. A.D.L., C.N.A., 13ºf., 1v. 239, fls. 28 29, 21 de Março de 1934. As instalações e alvará de exploração desta empresa vão ser adquiridos pela recém-constituída sociedade de "Resinagem Nacional, Lda.". Veja-se: A.D.L., C.N.A., $13^{\circ}$ of., lv. 279, fls. 41-44, 22 de Abril de 1936; 13o of., 1v. 280, fls. 23-25, 25 de Abril de 1936; $13^{\circ}$ of., lv. 281, fls. 6-8, 9 de Maio de 1936. A "Resinagem Nacional" adquire ainda o alvará de uma empresa de destilação de resinas sedeada na Maceira. A.D.L., C.N.A., $13^{\circ}$ of., lv. 292, fls. 6-7, 23 de Dezembro de 1936.

${ }^{75}$ Veja-se: Maria Carlos Baptista. (1987). A Agronomia Portuguesa no Século XIX... cit.., p. 381; Maria Carlos Baptista, "A Silvicultura em Portugal no Século XIX” in Ler História, 22 (1991), p. 60. 
resinado; que a grossura do pinheiro a resinar não poderá ser inferior a $25 \mathrm{~cm}$, com medição sobre a casca; que a ferida deverá obedecer à seguinte tabela: altura $45 \mathrm{~cm}$, largura $16 \mathrm{~cm}$, profundidade $1 \mathrm{~cm} . . . " 76$

\section{Conclusão}

No povoamento florestal dos coutos, o carvalho é a árvore dominante. As grandes matas que enfeitavam a Serra dos Candeeiros, começaram, a partir de meados do século XVII, a ser amputadas no seu esplendor, dando lugar a um amplo corredor de olival. No alvor do século XIX, a maior mancha desta essência tem lugar no Vimeiro. Mas a integridade destas matas já não é garantida no fim de vida do Mosteiro. São os cortes para o arsenal da marinha, a actividade dolosa dos carvoeiros, a extracção da casca para a indústria de curtumes, a procura de lenhas pelos povos, as clareiras que os camponeses aproveitam para amanho...

Por volta das décadas de 40 e 50 do século XIX, esta floresta conhece uma das maiores sangrias, hecatombe ecológica que dita a mudança do regime de exploração. Do alto fuste passa-se ao sistema de talhadio. A monocultura, outrora sustentável, ameaça, agora, exaurir o solo. As revoluções de 20 em 20 anos esgotam os nutrientes, a esmoita e as raspas da camada superficial também contribuem para a atrofia do carvalhal, o oídio dá uma ajuda a este cenário de decrepitude, as toiças morrem e as feridas na mata avolumam-se irremediavelmente. As suas madeiras vão ainda sentir os graves derrotes decorrentes da conjuntura económica da primeira guerra mundial, a concorrência de novas espécies como o pinheiro-bravo, o pinheiro manso, o castanheiro, o eucalipto e, por último, a pressão da pomicultura. Outros núcleos de menor dimensão como a mata da Infesta (Granja do Campo) sofrem, entre finais da década de 80 e princípios da de 90 , o arroteamento e emparcelamento.

Os soutos, mais cercanos ao Mosteiro, instalam-se nas encostas e cumeadas. Exceptuando alguns castanheiros sementões que emergem na mata densa, o regime de exploração baseia-se no corte da vararia para arcos e ripas (tanoaria e canastraria). A mudança de mãos da propriedade, com o termo do Antigo Regime, não teve repercussões neste tipo de economia florestal. A abundância de soutos de corte origina sucessivas migrações de canastreiros, desde a segunda metade do século XIX às primeiras décadas do século XX. Esta arte alimenta a vitalidade do souto, mas com a morte das artes e ofícios da canastraria por

\footnotetext{
${ }^{76}$ A.D.L., Cartório Notarial da Nazaré, lv. 126 ou 8, fls. 7-9, 21 de Fevereiro de 1901.
} 
meados do século XX, o povoamento dos soutos vai ser, em grande medida, tomado pelo eucalipto.

As sementeiras de pinheiro-bravo no litoral dos coutos respondem à exigência crescente de lenhas e madeiramentos, assim como a um plano de protecção dos terrenos de cultivo do avanço dunar e dos ventos mareiros. Mas a mancha de pinhal alastra noutras direcções, assenhoreando-se de áreas dedicadas às folhosas, aos bastios, a campos empobrecidos pelas culturas cerealíferas, aos baldios que escaparam à demanda olivícola e até ao chão de olival que ano após ano mingua na produção.

A floresta monocultural de crescimento rápido adequa-se à filosofia económica dos novos tempos. Do pinhal do Valado e do Santíssimo, a partir de meados do século XIX, são transportadas, diariamente, no comboio americano, muitas carradas de madeiras para embarque no cais de S. Martinho. As indústrias que se vão instalando no concelho entre os finais do século XIX e as primeiras décadas do século XX, nomeadamente a Companhia de Fiação e Tecidos de Alcobaça, a Empresa Cerâmica de Alcobaça e a Empresa Vidreira de Pataias, já não contando com a notável profusão de fornos de cal, de carvão e de telha que assentam arraiais no seio do coberto florestal, requerem, cada vez mais, matéria-prima para abastecer as suas ávidas caldeiras. A linha de caminho-de-ferro do Oeste surge, igualmente, como um motor à exportação das lenhas e madeiras dos pinhais. Por seu turno, o aproveitamento da resina constitui outro ganho substantivo e o pinhal fixa mão-de-obra entre serradores, motaneiros e, resineiros...

Perde-se a floresta ecologicamente sustentável, abrigo de uma diversidade arbórea, de um largo espectro florístico, de uma fauna selvagem, disponível ao pascigo dos gados e rabisco, entre tantas outras actividades. A própria lavoura tão dependente dos seus préstimos emancipa-se graças ao triunfo da química e de um paradigma de exploração que tem como alvo preferencial o mercado. A floresta primitiva desaparece gradualmente no espaço porque, com a aproximação inexorável da civilização industrial, deixa de ser útil e rentável. 
